\title{
Video-assisted breast surgery and sentinel lymph node biopsy guided by three-dimensional computed tomographic lymphography
}

\author{
K. Yamashita $\cdot$ K. Shimizu
}

Published online: 1 September 2007

(C) Springer Science+Business Media, LLC 2007

\section{Erratum to: Surg Endosc}

DOI 10.1007/s00464-007-9407-5

The correct version of Fig. 2(a) is hereby reproduced.

The online version of the original article can be found under doi: $10.1007 / \mathrm{s} 00464-007-9407-5$

\section{K. Yamashita $(\bowtie)$}

Department of Surgery, Nippon Medical School Musashikosugi

Hospital, 1-396 Kosugi-cho, Nakahara-ku, Kawasaki,

Kanagawa 211-8533, Japan

e-mail: yamasita@nms.ac.jp

\section{K. Shimizu}

Division of Endocrine Surgery, Department of Surgery,

Nippon Medical School, 1-5, Sendagi-1, Bunkyo-ku,

Tokyo 113-8602, Japan

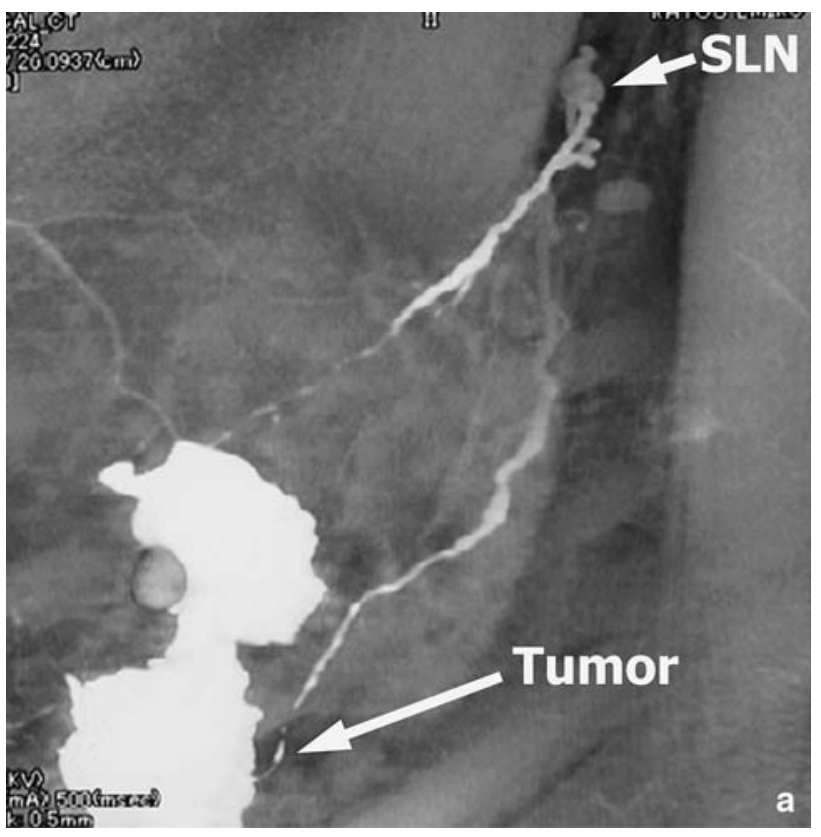

Fig. 2 Three-dimensional computed tomographic (3D-CT) lymphography. Iopamidol $(2 \mathrm{ml})$ was injected intracutaneously into the periareolar skin and the skin above the tumor. Lymph ducts and the sentinel lymph node (SLN) are visualized with 3D-CT lymphography. The lymph ducts are draining lymph each from periareola and the tumor into a single SLN 